\title{
THE BRITISH JOURNAL OF PSYCHIATRY
}

\section{The Journal of Mental Science}

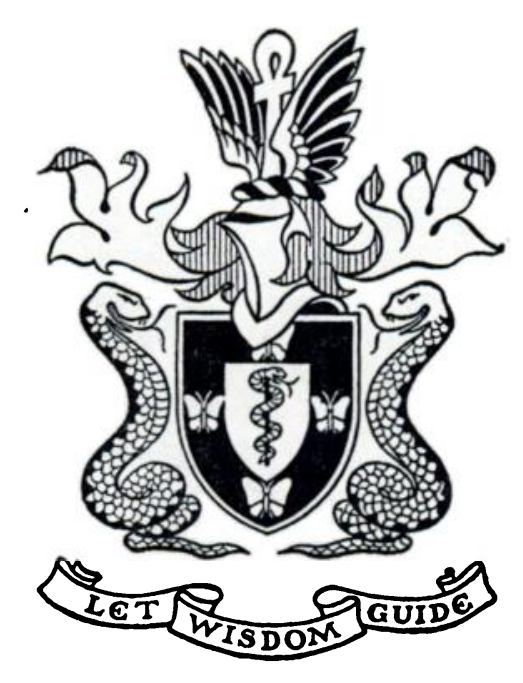

Published by authority of The Royal College of Psychiatrists

Index to Volumes I 26 and I 27

Ashford, Kent

HEADLEY BROTHERS LTD.

1975 
PRINTED IN GRIAT BRITAIN BY

TEA DLEY BROTHERS LTD

IO9 KINGSWAY LONDON WC2B 6PX

AND ABHFORD KENT TN24 8 HH

https://doi.org/10.1192/S0007125000071191 Published online by Cambridge University Press 